\section{Update from the Ophthalmology Child Abuse Working Party: Royal College Ophthalmologists}

G Adams, J Ainsworth, L Butler, R Bonshek, M Clarke, R Doran, G Dutton, M Green, P Hodgkinson, J Leitch, C Lloyd, P Luthert, A Parsons, J Punt, D Taylor, N Tehrani and $\mathrm{H}$ Willshaw(Chairman) for Child Abuse Working Party

Eye (2004) 18, 795-798. doi:10.1038/sj.eye.6701643

Published online 25 June 2004

In dealing with suspected child abuse, the ophthalmologist is often faced with interpreting clinical signs for which there is inadequate explanation in the history. Acknowledgement of abuse is rare, and interpretation of these findings and particularly extrapolation from them to an assessment of their causation has to be undertaken with care. The interests of the child are paramount, but we cannot ignore the impact of unwarranted accusations on a family. ${ }^{1}$ The courts rely upon their medical advisors to provide a balanced opinion, based on the best available evidence; 'Most judges have no more medical expertise than the average intelligent lay person' and judges 'are best assisted by experts who provide opinions based firmly on clinical findings and recognised medical knowledge'.2

We present a consensus opinion of developments in child abuse relevant to the Ophthalmologist since the last Working Party publication. ${ }^{3}$

Can normal handling (such as vigorous play) cause retinal and intracranial haemorrhages?

In 2001, Geddes et $a l^{4,5}$ reported the results of histopathological examination of the central nervous system (CNS) following fatal head injuries in 37 infants and 16 children.

These papers have been interpreted by sections of the press ${ }^{6}$ and some experts as suggesting that minor trauma, such as might occur during rough play, could cause the clinical picture commonly attributed to the Shaken Baby Syndrome (SBS). The Geddes papers showed that, in infants with inflicted head injury, there was evidence of hypoxic/ ischaemic neuronal damage rather than the diffuse axonal changes associated with traumatic brain injury. This concept is supported by neuroimaging. ${ }^{7,8}$ In 13 of 37 suggested that this injury to the respiratory centres had a role in producing hypoxia and brain damage.

These papers raise the possibility of alternative explanations for the observed pathology. While previously, it was assumed that the forces used must be sufficient to cause shearing injury, it is now apparent that shearing is not the sole pathogenesis of the changes seen in the brain (Geddes et al specifically excluded discussion of the aetiology of retinal haemorrhages). Although the precise level of force required to cause retinal haemorrhages remains uncertain, the majority of these children were unequivocally the victims of severe trauma. Despite having access to 'full documentation' in 52 cases, the authors did not cite a case in which they could link a less than violent event with fatal head injury. Nonetheless, in 8 infants there was no bruising, skull fracture, or extracranial injury to specifically indicate a violent event.

Since our previous report, ${ }^{3}$ it is now appreciated that evidence from mechanical models ${ }^{9}$ may reveal an imperfect picture of the events occurring during injury. ${ }^{10}$ It has been conceded that, 'whilst controversy still exists as to the exact mechanism, most authors now agree that the forces necessary to cause this type of injury are far from trivial and, in fact, are considerable' and 'that this sort of injury is unlikely to be inflicted 'accidentally' by infants reported by Geddes, ${ }^{5}$ there was axonal damage at the cranio-cervical junction. It was
Children's Hospital Birmingham, UK

Correspondence: $\mathrm{H}$ Willshaw

Child Abuse Working Party Royal College of Opthalmologists Children's Hospital Steel house Lane Birmingham B4 6NH, UK Tel/Fax: + 441564702438 E-mail: harry.willshaw@ bch.nhs.uk

Received: 10 November 2002

Accepted: 14 May 2004 Published online: 25 June 2004 
well-meaning carers who do not know that their behaviour can be injurious' ${ }^{11}$

Conclusion: It is highly unlikely that the forces required to produce retinal haemorrhage in a child less than 2 years of age would be generated by a reasonable person during the course of (even rough) play or an attempt to arouse a sleeping or apparently unconscious child.

\section{Do high cervical injuries from any other source give rise to retinal haemorrhages?}

In a study of the vegetative reactions of infants undergoing cervical manipulation ${ }^{12}$ apnoea occurred in 22. $1 \%$ of 199 children. This may be pertinent to the SBS, but no child progressed to the cascade of neurological sequelae associated with SBS. There seems no reason to believe that apnoea from cervical injury alone is sufficient to replicate the clinical picture of SBS. A group of children ${ }^{13}$ with a mean age of 6.3 years presented with multiple injuries and cardio-respiratory collapse, which could not be explained by blood loss. Of the 19 children, 18 died, and post mortem studies in 16 showed significant cord laceration (up to transection) in 13 . Neither subdural nor retinal haemorrhages were commented on in this report.

Conclusion: Cervical injuries alone do not give rise to retinal bleeding. However, cervical injuries in small children may produce apnoea. Inflicted cervical spine injury coupled with circulatory collapse has the potential to induce hypoxic/ischaemic encephalopathy.

\section{Does hypoxia give rise to the clinical picture of SBS?}

The suggested consequences of axonal injury at the cranio-cervical junction are apnoea followed by hypoxia. However, in the absence of circulatory collapse or the vascular changes associated with high altitude, ${ }^{14}$ acute hypoxia alone is insufficient to cause subdural and retinal bleeding. Similarly, acute hypoxia similar to that which occurs in smothering, while commonly causing petechial haemorrhages on the surface of the lungs, heart, and occasionally other viscera, has not been shown to cause retinal haemorrhages. ${ }^{15}$

It has been suggested that intradural and juxtadural bleeding in children dying from nontraumatic, hypoxic conditions, provides an explanation for the subdural bleeding in SBS. ${ }^{16}$ In all, $72 \%$ of cases had intradural and juxtadural bleeding histologically identical to that found in three cases of SBS. However, these children suffered 'profound' hypoxia before birth for various reasons including bronchopneumonia and placental insufficiency. There is no indication in this study that apnoea from localised axonal damage can produce a similar picture. The authors hypothesise a sequence of events where severe hypoxia leads to brain swelling, raised intracranial pressure, subsequent subdural, and retinal haemorrhage.

Conclusion: Acute hypoxia resulting from transient apnoea has not been shown to result in the SBS picture. Hypoxia coupled with circulatory collapse may produce potentially fatal brain swelling.

\section{Can short-distance falls cause retinal haemorrhage?}

The ALSPAC (Avon Longitudinal Study of Parents and Children) study of a West of England birth cohort collected data on 3357 falls in infants less than 6 months of age. ${ }^{17}$ Of the visible injuries noted following these falls, $97 \%$ involved the head and yet less than $1 \%$ resulted in fracture or concussion. The great majority of the falls were short distance and only 162 were taken to hospital with 16 requiring admission. If the children attending hospital are a small minority of those sustaining accidental injury, and if only a tiny minority of those children attending hospital show evidence of neurological or ocular damage, ${ }^{18,19}$ then the possibility of minor injury causing massive neurological damage and retinal bleeding must be remote.

A study of 93 children under the age of 3 years, admitted to two tertiary referral centres suffering from either subdural or epidural haemorrhage, found a strong association between the subdural location of haemorrhage and NAI. ${ }^{20}$ In all, $47 \%$ of children who were the victims of abuse had subdural bleeding compared to $6 \%$ with epidural bleeding. The authors discussed the biomechanics of the injuries, and concluded that linear impact injury may lead to tearing of vessels that are 'adherent to and tightly encased in the potential space between the skull and dura'; this results in epidural bleeding. The vessels involved in subdural bleeding are less tightly bound and therefore less vulnerable to direct impact but susceptible to tearing when exposed to complex rotational forces (such as that which might occur when the head is free to rotate around the axis of the neck).

A review from a children's neurosurgical service ${ }^{21}$ similarly suggested that short-distance falls were likely to cause extradural rather than subdural bleeding. They identified 40 cases (from a total of 211) of children less than 3 years with extradural haemorrhage. The mechanisms of trauma were falls from less than $1 \mathrm{~m}$ (40\%) falls from greater than $1 \mathrm{~m}(30 \%)$ and falls while walking $(17.5 \%)$. No children had a concomitant subdural haematoma and there were no cases of nonaccidental causation.

In contrast, of 33 children presenting in South Wales with subdural haemorrhage, 27 were 'highly suggestive of abuse'.$^{22}$ The evidence of abuse included fractures, 
torn frenulum, burns, and adult bite marks. A similar study from the United States ${ }^{23}$ again concluded that fatal injuries following reports of minor falls were usually found ultimately to result from abuse.

Against this background of evidence, two recent studies have documented retinal haemorrhages resulting from short-distance falls. ${ }^{24,25}$ The first report, of three children, documented unilateral retinal haemorrhages in all three, with the haemorrhages ipsilateral to the intracranial haemorrhage and confined to the posterior pole. In each case, the retinal haemorrhages were relatively mild and did not extend to the ora serrata.

In the second report, the United States Consumer Product Safety Commission National Injury information was scrutinised for all head and neck injuries involving playground equipment over a period of 11.5 years. This included more than 75000 files and identified 18 deaths from head injuries. Eight of the dead children were 3 years old or less, and in three of them bilateral retinal haemorrhages were documented. The limitations of the study were acknowledged by the author. In only two of these cases affecting young children was the causative event witnessed by a person other than the adult carer. Furthermore, the method of calculating the distance fallen meant that the calculation was very imprecise, so that in the case of falls involving swings, the distance could vary between 0.6 and $2.4 \mathrm{~m}$.

It seems clear that minor falls can, only exceptionally, give rise to subdural and retinal bleeding. In these cases, it may well be that the biomechanics of the impact induce the rotational forces necessary to produce the picture considered typical of SBS.

Conclusion: Abusive shaking (with or without impact) is the most likely cause of subdural haemorrhage and retinal haemorrhage in children admitted to hospital. Rarely, accidental trauma may give rise to a similar picture. In a child with retinal haemorrhages and subdural haemorrhages who has not sustained a high velocity injury and in whom other recognised causes of such haemorrhages have been excluded, child abuse is much the most likely explanation. A careful search for other evidence of nonaccidental injury is mandatory.

\section{Are retinal haemorrhages secondary to intracranial bleeding?}

Since retinal haemorrhages frequently coexist with subdural haemorrhages in severely damaged children, ${ }^{26}$ the question often asked is did the same traumatic event cause bleeding in both sites, or did the retinal haemorrhages develop secondary to the intracranial bleeding.
Terson syndrome ${ }^{27}$ describes ocular haemorrhage in association with subarachnoid haemorrhage, but is now expanded to include intraocular bleeding associated with any form of intracranial bleeding. It affects between 16 and $27 \%$ of adult patients. ${ }^{28,29}$ Schloff $e t$ al ${ }^{30}$ investigated, prospectively, 57 children aged 5 months-16.1 years (mean age 10.3 years), seen with intracranial bleeding. In total, 26 of the children had undergone neurosurgery, and 27 were the victims of trauma. Of the total group, 96\% (55 children) showed no evidence of intraocular bleeding, despite $18 \%$ having papilloedema. Of the two children with intraocular bleeding, one 7-year-old child had three superficial retinal haemorrhages following a road traffic accident in which he was thrown $100 \mathrm{ft}$ from the vehicle. The second, an 8-year-old, had a single dot retinal haemorrhage, and this child was heparinised, had sepsis, and had suffered an intraventricular haemorrhage.

Conclusion: Terson syndrome is rare in children and haemorrhages if they occur tend to be concentrated around the optic disc.

\section{Summary}

We believe this current review complements and updates our previous report and offers a balanced assessment of the new information available. It will be necessary to reevaluate the situation regularly in the light of new research.

Statement of interest: The members of the Working Party are all, from time to time, called as witnesses in cases of suspected nonaccidental injury and may receive remuneration for their evidence.

\section{References}

1 Clark BJ. Retinal haemorrhages: evidence of abuse or abuse of evidence? Am J Forensic Med Pathol 2001; 22: 415-416.

2 Butler-Sloss E, Hall A. Expert witnesses, courts and the law. J Roy Soc Med 2002; 95: 431-434.

3 Ophthalmology Child Abuse Working Party. Child abuse and the eye. Eye 1999; 13: 3-10.

4 Geddes JF, Hackshaw AK, Vowles GH, Nickols CD, Whitwell HL. Neuropathology of inflicted head injury in children. 1. Patterns of brain damage. Brain 2001; 124: 1290-1298

5 Geddes JF, Hackshaw AK, Vowles GH, Nickols CD, Scott IS, Whitwell HL. Neuropathology of inflicted head injury in children. 11. Microscopic brain injury in infants. Brain 2001; 124: 1299-1306.

6 Coghlan A, Le Page M. Gently does it. New Scientist 2001; 16th June: $4-5$.

7 Biousse V, Suh DY, Newman NJ, Davis PC, Mapstone T, Lambert SR. Diffusion-weighted magnetic resonance imaging in Shaken Baby Syndrome. Am J Ophthalmol 2002; 133: 249-255. 
8 Jaspan T, Griffiths PD, McConachie NS, Punt JAG. The Trent NAI Group Neuroimaging for non-accidental head injury in childhood: a proposed protocol. Clin Radiol 2003; 58: 44-53.

9 Duhaime A-C, Gennarelli TA, Thibault LE, Bruce DA, Margulies SS, Wiser R. The shaken baby syndrome. A clinical, pathological and biomechanical study. J Neurosurg 1987; 66: 409-415.

10 Ommaya AK, Goldsmith W, Thibault L. Biomechanics and neuropathology of adult and paediatric head injury. $\mathrm{Br} \mathrm{J}$ Neurosurg 2002; 16: 220-242.

11 Duhaime A-C, Christian C. Nonaccidental trauma. In: Choux M, Rocco C, Hockley A, Walker M (eds). Paediatric Neurosurgery. Churchill Livingstone: London, 1999 pp. 373-379.

12 Koch LE, Biedermann H, Saternus KS. High cervical stress and apnoea. Forensic Sci Int 1998; 97: 1-9.

13 Bohn D, Armstrong D, Becker L, Humphreys R. Cervical spine injuries in children. J Trauma 1990; 30: 463-469.

14 Mullner-Eidenbock A, Rainer G, Strenn K, Zidek T. Highaltitude retinopathy and retinal vascular dysregulation. Eye 2000; 14: 724-729.

15 Oohmichen M, Gerling I, Meissner C. Petechiae of the baby's skin as differentiation symptom of infanticide versus SIDS. J Forensic Sci 2000; 45: 602-607.

16 Geddes JF, Tasker RC, Hackshaw AK, Nickols CD, Adams GGW, Whitwell HL et al. Dural haemorrhage in nontraumatic infant deaths: does it explain the bleeding in 'shaken baby syndrome'? Neuropathol Appl Neurobiol 2003; 29: 14-22.

17 Warrington SA, Wright CM, ALSPAC study team. Accidents and resulting injuries in premobile infants: data from the ALSPAC study. Arch Dis Child 2001; 85: 104-107.

18 Maddocks GB, Sibert JR, Brown BM. A four week study of accidents to children in South Glamorgan. Public Health 1978; 92: 171-176.

19 Rivana FP, Kamitsulka MB, Quai L. Injuries to children younger than 1 year of age. Paediatrics 1988; 81: 93-97.
20 Shugerman RP, Paez A, Grossman DC, Feldman KW, Grady MS. Epidural hemorrhage: is it abuse? Pediatrics 1996; 97: 664-668.

21 Leggate JRS, Lopez-Ramos N, Genitori L, Lena G, Choux M. Extradural haematoma in infants. Br J Neurosurg 1989; 3: 533-540.

22 Jayawant S, Rawlinson A, Gibbon F, Price J, Schulte J, Sharples $\mathrm{P}$ et al. Subdural haemorrhages in infants: population based study. BMJ 1998; 317: 1558-1561.

23 Reiber GD. Fatal falls in childhood. How far must children fall to sustain fatal head injury? Report of cases and review of the literature. Am J Forensic Med Pathol 1993; 14: 201-207.

24 Christian CW, Taylor AA, Hertle RW, Duhaime A-C. Retinal hemorrhages caused by accidental household trauma. J Pediatr 1999; 135: 125-127.

25 Plunkett J. Fatal pediatric head injuries caused by shortdistance falls. Am J Forensic Med Pathol 2001; 22: 1-12.

26 Green MA, Lieberman G, Milroy CM, Parsons MA. Ocular and cerebral trauma in non-accidental injury in infancy: underlying mechanisms and implications for paediatric practice. Br J Ophthalmol 1996; 80: 282-287.

27 Terson A. Le syndrome de corps vitre et de l'hemorrhagie intracranienne spontane. Ann Oculist 1926; 163: 666-673.

28 Garfinkle AM, Danys IR, Nicolle DA, Colohan AR, Brem S. Terson's syndrome: a reversible cause of blindness following subarachnoid hemorrhage. J Neurosurg 1992; 76: 766-771.

29 Pfausler B, Belcl R, Metzler R, Mohsenipour I, Schmutzhard E. Terson's syndrome in spontaneous subarachnoid hemorrhage: a prospective study of 60 consecutive patients. J Neurosurg 1996; 85: 392-394.

30 Schloff S, Mullaney PB, Armstrong DC, Simantirakis E, Humphreys RP, Myseros JS et al. Retinal findings in children with intracranial hemorrhage. Ophthalmology 2002; 109: 1472-1476. 